\title{
Padrão de atividade e comportamento de forrageamento do morcego-pescador Noctilio leporinus (Linnaeus) (Chiroptera, Noctilionidae) na Baía de Guaratuba, Paraná, Brasil
}

\author{
Marcelo O. Bordignon ${ }^{1}$ \\ Departamento de Ciências do Ambiente, Universidade Federal de Mato Grosso do Sul. Caixa Postal 252, \\ 79304-020 Corumbá, Mato Grosso do Sul, Brasil. E-mail: batbull@bol.com.br
}

\begin{abstract}
Activity pattern and foraging behavior of bulldog-bat Noctilio leporinus (Linnaeus,) (Chiroptera, Noctilionidae) in Guaratuba Bay, Paraná State, Brazil. From January 18 to December 16 of 1999 the foraging behavior and activity pattern of fishing bat Noctilio leporinus (Linnaeus, 1758) were studied in mangrove ecosystem of Guaratuba Bay, southern Brazil. The groups of N. leporinus observed remained active during all nightly period but showed an apparent bimodal pattern. During April and September $N$. leporinus generally begin their activity at 18:00h, one hour earlier than October to March months, when their activity started at 19:00 h. The foraging behavior on fish shoal varied spatially along all the activity period. During low tide level the bat groups remained fishing distant from margin on deeper water, but during high tide level the bats were always observed fishing close to the margin on flat water. This pattern in foraging behavior of $N$. leporinus appears to be determined by the fish shoal displacement pattern in Guaratuba Bay.

KEY WORDS. Fishing diet; mangrove; piscivory; Rain Forest; tide level.
\end{abstract}

RESUMO. Entre 18 de janeiro a 16 de dezembro de 1999 foi estudado o comportamento de forrageamento e o padrão de atividade do morcego-pescador Noctilio leporinus (Linnaeus, 1758), em uma área de manguezal na Baía de Guaratuba, Sul do Brasil. Os grupos de N. leporinus observados permaneceram em atividade ao longo de todo o período noturno, mas com um aparente padrão bimodal. Durante os meses de abril a setembro, $N$. leporinus inicia a sua atividade geralmente às 18:00 $\mathrm{h}$, uma hora mais cedo do que durante os meses de outubro a março, quando inicia sua atividade geralmente às 19:00 h. O comportamento de predação sobre os cardumes de peixes mostrou variações quanto ao local de forrageamento ao longo do período de atividade. Em baixos níveis de maré, os grupos de morcegos pescaram longe da margem em águas mais profundas, mas nos níveis de maré alta os grupos de morcegos permaneceram pescando sempre junto à margem, em águas mais rasas. Este padrão de comportamento em $N$. leporinus parece ser determinado pelo padrão de deslocamento dos cardumes de peixes na área de estudo. PALAVRAS CHAVE. Floresta Atlântica; manguezal; piscivoria; sardinhas.

A ordem Chiroptera possui a maior variedade de hábitos alimentares dentre os mamíferos, incluindo adaptações particulares, tais como a sanguivoria e a piscivoria (Kunz 1988, Ferrarezzi \& Gimenez 1996). Dentre as poucas espécies piscívoras Myotis vivesi Menegaux, 1901 e Myotis ricketti Thomas, 1894 (Nowak 1994, Blood \& Clark 1998, Ma et al. 2003), Noctilio leporinus (Linnaeus, 1758) está entre as mais bem adaptadas a piscivoria (Hood \& Jones 1984), incluindo uma grande variedade de peixes e crustáceos em sua dieta (Novick \& Dale 1971, Brooke 1994, Bordignon \& FANÇA 2002). De ampla distribuição neotropical, esta espécie ocupa tanto os biomas de água doce quanto áreas estuarinas marinhas, do Caribe até a Argentina (Koopman 1982, Emmons \& Feer 1990, Fenton 1992).

As adaptações anatômicas para a captura de peixes, tais como garras grandes em forma de foice e membros posteriores longos, aliadas a um sistema de ecolocalização de grande sensibilidade, capaz de detectar peixes por meio da turbulência exercida pelos cardumes junto à superfície d'água, possibilitam-lhe uma grande eficiência na captura destas presas (SUTHERS 1965, Altenbach 1989, Fish et al. 1991, SChnitzler et al. 1994). Apesar do comportamento piscívoro deste morcego já ser conhecido desde 1860 (Villa-Ramirez 1966), poucos são os estudos que buscaram avaliar seu comportamento de forrageio e estratégias de captura de presas.

No nordeste do Brasil, Willig (1985) verificou que $N$. leporinus consome peixes e insetos, porém não especifica quais são, nem a freqüência com que estes itens ocorrem na sua dieta. No sudeste, Zórtea \& Aguiar (2001) fizeram um relato breve sobre o consumo de insetos por esta espécie, em lagoas de água doce. No México, Cervantes \& Solorzano (1991), mostraram que

Revista Brasileira de Zoologia 23 (1): 50-57, março 2006 
a análise de conteúdo estomacal para a avaliação da dieta desta espécie é um método que produz poucos resultados. Em Porto Rico, BRooke $(1994,1997)$ verificou que N. leporinus forrageiam em pequenos grupos, consumindo cerca de $50 \%$ de peixe em sua dieta, além de insetos. Mais recentemente no sul do Brasil, BordignON \& FrançA (2002) constataram que esta espécie inclui em sua dieta piscívora principalmente peixes das famílias Atherinopsidae, Mugilidae, Engraulidae e Clupeidae.

Estudando N. leporinus em cativeiro, SuTHERs (1965) constatou que a detecção de objetos sobre a superfície d'água é feita apenas pela ecolocalização e SCHNitzler et al. (1994) observaram que $N$. leporinus, além de utilizar diferentes freqüências sonoras para localizar suas presas quando sobrevoa a superfície da água, também memoriza as áreas onde obteve melhor sucesso de captura de peixes.

Como os estudos mais detalhados sobre a biologia de $N$. leporinus são relativos às regiões da América Central e Caribe (Handley 1976, Jones et al. 1973, La VAl \& Fitch 1977, Novick \& DALE 1971, Brooke 1994), o objetivo do presente estudo foi contribuir para um melhor conhecimento sobre a ecologia comportamental desta espécie, por meio da observação e registro do padrão de atividade noturna e do comportamento de forrageio em um ecossistema de manguezal no sul do Brasil.

\section{MATERIAL E MÉTODOS}

\section{Área de estudo}

A Baía de Guaratuba situa-se no litoral Sul do Estado do Paraná (2550' S; 48 34' W), ligando-se ao mar por uma abertura de aproximadamente $500 \mathrm{~m}$, estendendo-se continente adentro, ao longo da planície litorânea por cerca de $15 \mathrm{~km}$. Este sistema estuarino é muito utilizado pelas comunidades locais para a pesca artesanal de subsistência e esportiva (CHAVEs \& VeNDEL 1997). Sua margem norte possui um rico manguezal (Fig. 1), com poços cuja profundidade atinge pelo menos $7 \mathrm{~m}$. A média mensal da temperatura da água varia de 16 a $30^{\circ} \mathrm{C}$ ao longo do ano e a salinidade raramente ultrapassa $30 \%$ (CHAves 1995).

A ictiofauna da região é aquela típica de ambientes marinhos e estuarinos, sendo particularmente comuns as espécies das famílias Ariidae, Haemulidae, Gerreidae, Sciaenidae, bem como das ordens Tetraodontiformes e Pleuronectiformes (CHAVEs 1994). Este ecossistema é considerado um "berçário", pois muitas espécies marinhas desovam neste local, o que proporciona uma grande quantidade de alevinos durante as estações do ano.

\section{Amostragem da atividade e do comportamento}

Durante o período de 18 de janeiro a 16 de dezembro de 1999 foram realizadas amostragens sazonais de observação do comportamento de forrageio, com períodos contínuos de quatro noites/mês, no horário das 17:00 às 07:00 h.

Em cada noite de amostragem, os dados da atividade noturna de forrageio foram coletados da seguinte forma: com um binóculo infravermelho (Russian Night Scout Smart - Night Vision Binoculars AMTc $\left.^{\circledR}\right)$, a cada período de uma hora

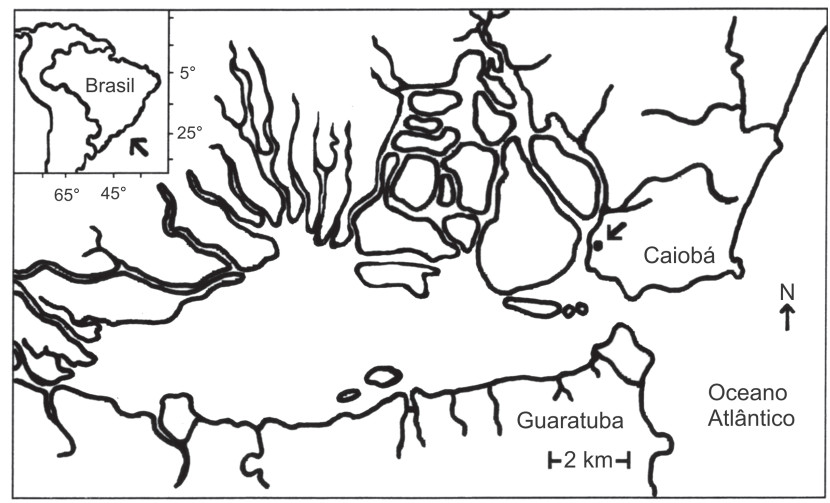

Figura 1. Mapa da Baía de Guaratuba, mostrando o local onde foram feitas as observações do comportamento de $N$. leporinus (seta). Modificado de Chaves et al. (1998).

visualizava-se todo o perímetro do canal em frente ao Iate Clube de Caiobá, durante cerca de cinco minutos, utilizando-se o método de amostragem do tipo "Scan" (Altman 1974). Eram registrados assim, em sessões de cinco minutos a cada hora, o número de animais avistados e sua posição na área de observação. A freqüência individual de sucesso na captura de peixes por cada morcego foi registrada pelo menos uma noite por mês, durante um período de 15 minutos utilizando-se o método de "animal focal" (Altman 1974), para cada morcego observado, considerava-se uma seção de observação. A freqüência de sucesso obtida em cada observação era estimada através do número de acertos dividido pelo número de tentativas realizadas por cada indivíduo. Posteriormente foi feita a correlação entre o numero de tentativas feitas por cada indivíduo e o número de acertos.

Localização e deslocamento dos morcegos durante a atividade de forrageamento

De acordo com a sua posição no local de forrageamento, os morcegos podiam estar localizados nos seguintes locais (Fig. 2): (a) margem - quando permaneciam em atividade de pesca a uma distância de 0 a $50 \mathrm{~m}$ da margem do canal, ou no interior da marina do Iate Clube de Caiobá; (b) canal - quando permaneciam em atividade de pesca a uma distância superior a $50 \mathrm{~m}$ da margem do canal. A largura do canal em frente ao local de observação era de $360 \mathrm{~m}$ entre uma margem e outra. As médias sazonais do número de animais avistados em atividade/hora foram comparadas através do teste " $\mathrm{t}$ " de Student.

\section{Condições meteorológicas e comportamento}

Em cada noite de amostragem era também registrada a cada período de uma hora, no horário das 17:00 às 07:00 h, as seguintes variáveis abióticas: o nível da maré em centímetros, por meio de uma régua fixada no limite de maré baixa; a temperatura do ar (medida com um termômetro digital) e a velocidade do vento (medida com um anemômetro mecânico). Estes dados foram posteriormente comparados com o número mé-

Revista Brasileira de Zoologia 23 (1): 50-57, março 2006 


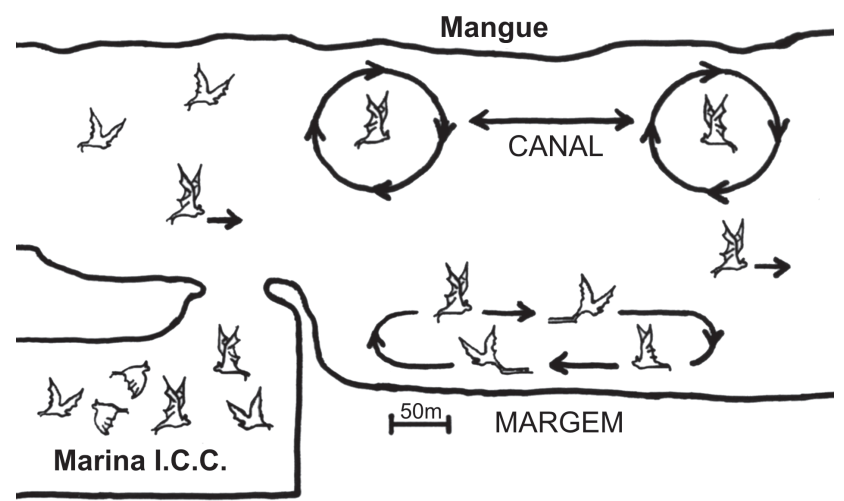

Figura 2. Representação esquemática dos locais onde foram avistados os exemplares de N. Leporinus durante sua atividade de pes$\mathrm{ca}$, junto ao late Clube de Caiobá, Paraná.

dio de animais observados em atividade de forrageio, a fim de se verificar possíveis correlações.

Nas noites em que ocorria chuva intensa e contínua, as amostragens não foram efetuadas, realizando-se novas noites de amostragens em períodos sem chuva. Esta atitude foi arbitrariamente tomada para evitar possíveis erros amostrais, os quais poderiam ser provocados pelas condições meteorológicas desfavoráveis.

\section{Disponibilidade de peixes}

Com o objetivo de avaliar a disponibilidade de peixes nos diferentes picos de nível de maré, junto à margem do local de estudo, foi realizada uma única amostragem noturna da ictiofauna local durante os picos da maré baixa e da maré alta. Foi utilizada uma rede-de-arrasto manual do tipo "picaré" com 30 x 1,20 m e malha $0,5 \mathrm{~mm}$. Os peixes coletados foram identificados em nível específico. O tamanho máximo e mínimo das espécies foi tomado, bem como a biomassa total de cada coleta.

\section{RESULTADOS}

\section{Padrão de atividade}

Durante o período de estudo, para um esforço de campo de 720 horas foi realizado um total de 60 horas de observação direta sobre a atividade noturna de $N$. leporinus. A média diária sazonal de animais avistados por hora variou entre as estações do ano. A menor média de avistagem foi registrada na estação de primavera (1,83 morcegos/sessão) e a maior média durante o inverno (4,83 morcegos/sessão), sendo também nesta estação a maior média de avistagem de morcegos (8,3 morcegos/ sessão) em atividade de forrageio (Tab. I).

Nos meses de verão, o início da atividade ocorreu a partir das 19:00 h, mais tarde do que durante os meses de outono, inverno e primavera; quando a atividade iniciou-se às 18:00 h na maior parte das amostragens. Nos meses de verão, a maior
Tabela I. Número médio de exemplares de $N$. leporinus avistados por sessão amostral em atividade de forrageamento, na Baía de Guaratuba, entre os meses de janeiro e dezembro de 1999.

\begin{tabular}{ccccc}
\hline Hora & $\begin{array}{c}\text { Verão } \\
\text { (jan-mar) }\end{array}$ & $\begin{array}{c}\text { Outono } \\
\text { (abr-jun) }\end{array}$ & $\begin{array}{c}\text { Inverno } \\
\text { (jul-set) }\end{array}$ & $\begin{array}{c}\text { Primavera } \\
\text { (out-dez) }\end{array}$ \\
\hline $17: 00$ & 0 & 0 & 0 & 0 \\
$18: 00$ & 0 & 6,6 & 8,30 & 0,83 \\
$19: 00$ & 3,40 & 5,8 & 5,00 & 4,50 \\
$20: 00$ & 5,20 & 4,5 & 4,50 & 3,80 \\
$21: 00$ & 4,40 & 3,3 & 6,80 & 2,60 \\
$22: 00$ & 5,00 & 3,6 & 5,30 & 2,60 \\
$23: 00$ & 2,40 & 2,5 & 5,30 & 1,60 \\
$00: 00$ & 2,00 & 3,0 & 5,30 & 0,83 \\
$01: 00$ & 2,60 & 2,8 & 3,80 & 1,50 \\
$02: 00$ & 3,00 & 1,3 & 3,80 & 1,66 \\
$03: 00$ & 3,40 & 1,5 & 3,30 & 2,10 \\
$04: 00$ & 2,80 & 2,3 & 6,30 & 1,00 \\
$05: 00$ & 0,80 & 2,1 & 4,00 & 0,83 \\
$06: 00$ & 0 & 0,5 & 1,16 & 0 \\
$07: 00$ & 0 & 0 & 0 & 0 \\
\hline Média & 2,69 & 3,06 & 4,83 & 1,83 \\
Desvio padrão & 1,690395 & 1,742383 & 1,767845 & 1,2746478 \\
\hline
\end{tabular}

média de animais avistados/hora foi registrada às 20:00 h e a menor às 05:00 h. Nos meses de outono e inverno, as maiores médias foram registradas nas primeiras cinco horas após o pôrdo-sol (entre 18:00 e 22:00 h). Já na primavera, a atividade dos morcegos apresentou-se similar àquela observada nos meses de verão.

Os valores encontrados na média do número de morcegos avistados/hora, entre as estações de verão e outono, não foram significativamente diferentes de acordo com o teste " $\mathrm{t}$ " de Student. Por outro lado, as demais estações do ano mostraram uma diferença significativa nas médias de avistagem (Tab. II).

Tabela II. Comparação entre as médias do número de morcegos avistados por sessão amostral, na Baía de Guaratuba, entre os meses de janeiro e dezembro de 1999, através do Teste " $t$ " de Student.

\begin{tabular}{cc}
\hline Estações confrontadas & Valor de p \\
\hline Verão x Outono & 0,565 \\
Verão x Inverno & $0,005^{*}$ \\
Verão x Primavera & $0,012^{*}$ \\
Outono x Inverno & $0,000^{*}$ \\
Outono x Primavera & $0,014^{*}$ \\
Inverno x Primavera & $0,000^{*}$ \\
\hline
\end{tabular}

* Valores significativos para $p<0,05$ 
A atividade noturna de $N$. leporinus na área de estudo mostrou um padrão bimodal ao longo do ano (Fig. 3), com um primeiro pico de atividade iniciando-se logo após o pôr-do-sol e outro após as 0:00 h (meia noite), o qual variou durante as estações, de duas a quatro horas antes do amanhecer.

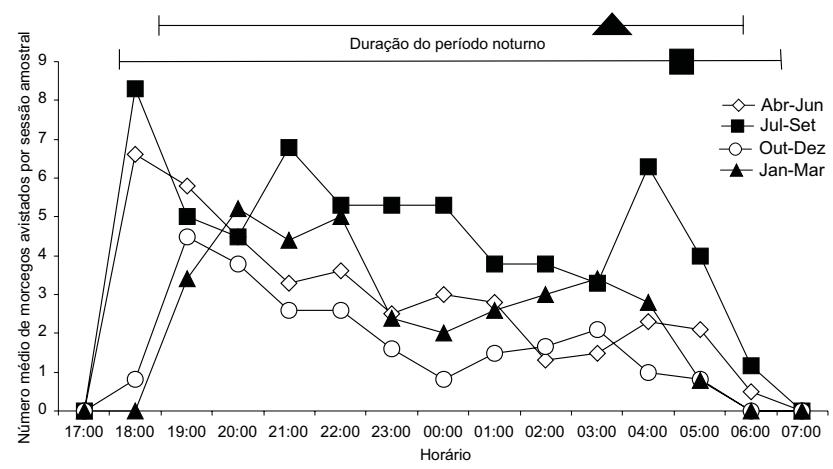

Figura 3. Padrão sazonal da atividade noturna de N. leporinus, representado pelo número médio de morcegos avistados por sessão, na Baía de Guaratuba, Paraná. As barras horizontais indicam a duração do período noturno nas estações de verão $(\mathbf{A})$ e inverno ( $\square$ ).

Durante os meses de primavera (outubro a dezembro), a atividade noturna iniciou-se às 18:00 h, atingindo o primeiro pico às 19:00 h. Já para os meses de verão (janeiro a março), a atividade noturna iniciou-se às 19:00 h, atingindo o primeiro pico às 20:00 h. O segundo pico de atividade ocorreu às 03:00 $\mathrm{h}$ da madrugada, decrescendo posteriormente até às 06:00 $\mathrm{h}$ tanto para os meses de verão quanto para os de primavera.

Durante os meses de outono (abril a junho) e inverno (julho a setembro), a atividade noturna iniciou-se às 18:00 h, quando também registrou o primeiro pico. O segundo pico ocorreu às 04:00 h, decrescendo posteriormente até às 07:00 h. Nos meses de inverno observou-se também que um decréscimo mais acentuado da atividade após o primeiro pico ocorreu após às 00:00 h, ao contrário dos meses de outono, primavera e verão, que ocorreu geralmente após às 22:00 h. Também durante os meses de inverno (julho a setembro), o número médio de morcegos em atividade ao longo de todo o período noturno foi maior que para as outras estações.

\section{Variação da maré e atividade de forrageamento}

Durante o período de estudo, os dados coletados sobre o número de morcegos em atividade de forrageio/hora e as oscilações no nível da maré, depois de comparados entre si, mostraram um padrão de comportamento que se repetiu ao longo das quatro estações do ano (Fig. 4).

Este padrão caracterizou-se pela mudança espacial da atividade de forrageio dos animais observados, conforme os ciclos de maré enchente ou vazante no local de estudo.

Durante o período da maré baixa, quando as águas da Baía vão para o Oceano e o nível médio oscila entre zero e $70 \mathrm{~cm}$, os morcegos foram avistados com maior freqüência forrageando no meio do canal em frente ao Iate Clube de Caiobá, sempre a uma distância maior que $50 \mathrm{~m}$ da linha de maré.

Quando o nível da maré subia, oscilando entre 70 e $180 \mathrm{~cm}$, os morcegos encontravam-se forrageando mais freqüentemente junto à margem do canal, geralmente a uma distância inferior a $50 \mathrm{~m}$ da linha de maré. Este padrão de comportamento relacionava-se sempre com o nível da maré e não com o horário de atividade.

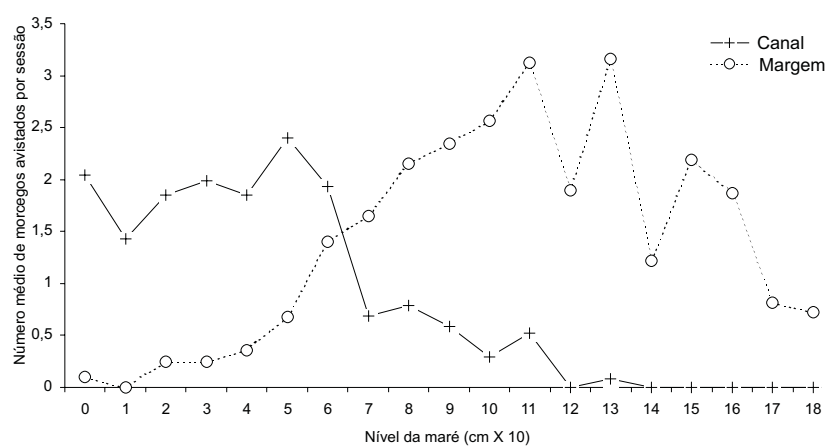

Figura 4. Atividade de pesca de N. leporinus e sua relação com o nível da maré, na Baía de Guaratuba, Paraná. Foram realizadas 22 sessões amostrais para cada nível de maré.

\section{Variação da maré e disponibilidade de peixes}

A biomassa e o número de espécies de peixes disponíveis junto à faixa de maré durante o período noturno, variou nos picos de maré baixa e alta (Tab. III).

Na maré baixa, a biomassa de peixes coletada foi de $1.598 \mathrm{~g}$ e totalizou 264 indivíduos de 10 espécies. Na amostragem de maré alta, a biomassa coletada foi de $2.853 \mathrm{~g}$ para um total de 526 indivíduos de 13 espécies. Na maré baixa, as três famílias com maior número de exemplares coletados foram respectivamente: Paralichtidae $(\mathrm{n}=150)$, Gerreidae $(\mathrm{n}=48)$, Atherinopsidae $(n=26)$. Já para a maré alta, as três famílias com o maior número de exemplares coletados foram: Atherinopsidae $(n=312)$, Clupeidae $(n=79)$, Paralichthydae ( $n=41)$ e Gerreidae $(n=40)$.

\section{Comportamento de captura de presas}

Durante o período de estudo, alguns aspectos do comportamento de $N$. leporinus puderam ser registrados. A captura de peixes pelos morcegos aparentava ser mais freqüente quando estes forrageavam junto à margem ou dentro da Marina do Iate Clube de Caiobá, no período de maré alta. Algumas vezes, vários morcegos realizavam vôos rasantes junto à superfície d'água, aparentando serem parte de um mesmo grupo social. Outras vezes, apenas um animal forrageava em uma mesma área, realizando manobras circulares ou elípticas junto à super- 
Tabela III. Espécies de peixes coletados com rede de arrasto na maré baixa (19:30 h) e maré alta (24:00 h), no dia 02 de maio de 2000, junto à faixa de maré no local de estudo.

\begin{tabular}{|c|c|c|c|c|c|}
\hline \multirow[b]{2}{*}{ Espécies } & \multirow[b]{2}{*}{ Nome popular } & \multicolumn{2}{|c|}{ Maré baixa $(n=264)$} & \multicolumn{2}{|c|}{ Maré alta $(n=526)$} \\
\hline & & n (\%) & $\begin{array}{l}\text { Comprimento } \\
\text { máx-mín }(\mathrm{mm})\end{array}$ & n (\%) & $\begin{array}{l}\text { Comprimento } \\
\text { máx-mín }(\mathrm{mm})\end{array}$ \\
\hline \multicolumn{6}{|l|}{ Atherinopsidae } \\
\hline Atherinella brasiliensis (Quoy \& Gaimard, 1824) & Peixe-rei & $26(9,8)$ & $105-60$ & $312(59,3)$ & $143-59$ \\
\hline \multicolumn{6}{|l|}{ Centropomidae } \\
\hline Centropomus parallelus Poey, 1860 & Robalo & $1(0,37)$ & 100 & $8(1,5)$ & $116-88$ \\
\hline \multicolumn{6}{|l|}{ Tetraodontidae } \\
\hline Sphoeroides testudineus (Linnaeus, 1758) & Baiacu-pintado & $14(5,3)$ & $59-1$ & $1(0,19)$ & 58 \\
\hline Sphoeroides greeleyi Gilbert, 1900 & Baiacu-mirin & $8(3,0)$ & $117-39$ & $1(0,19)$ & 46 \\
\hline \multicolumn{6}{|l|}{ Grammistidae } \\
\hline Rypticus randalli Courtenay, 1967 & Peixe-sabão & $4(1,5)$ & $121-48$ & - & - \\
\hline \multicolumn{6}{|l|}{ Gerreidae } \\
\hline Eucinostomus argenteus Baird \& Girard, 1854 & Escrivão & $47(17,8)$ & $89-50$ & $37(7,0)$ & $102-58$ \\
\hline Eucinostomus gula (Cuvier, 1830) & Escrivão & $1(0,37)$ & 95 & $3(0,57)$ & $111-77$ \\
\hline \multicolumn{6}{|l|}{ Gobiidae } \\
\hline Gobionellus stigmaticus (Poey, 1861) & Maria-da-toca & $11(4,16)$ & $41-23$ & $7(1,3)$ & $44-29$ \\
\hline \multicolumn{6}{|l|}{ Cynoglossidae } \\
\hline Symphurus tessellatus (Quoy \& Gaimard, 1824) & Língua-de-mulata & $2(0,75)$ & $95-48$ & - & - \\
\hline \multicolumn{6}{|l|}{ Paralichthidae } \\
\hline Citharichthys arenaceus Evermann \& Marsh, 1900 & Linguado & $150(56,8)$ & $150-28$ & $41(7,8)$ & $132-48$ \\
\hline \multicolumn{6}{|l|}{ Carangidae } \\
\hline Chloroscombus crysurus (Linnaeus, 1766) & Palombeta & - & - & $2(0,38)$ & 57 \\
\hline \multicolumn{6}{|l|}{ Mugilidae } \\
\hline Mugil curema (Valenciennes, 1840) & Tainha & - & - & $28(5,3)$ & $116-78$ \\
\hline \multicolumn{6}{|l|}{ Engraulidae } \\
\hline Cetengraulis edentulus (Cuvier, 1829) & Manjuba & - & - & $7(1,3)$ & $112-94$ \\
\hline \multicolumn{6}{|l|}{ Clupeidae } \\
\hline Harengula clupeola Cuvier, 1829) & Sardinha & - & - & $61(11,6)$ & $85-66$ \\
\hline Opistonema oglinum (Lesueur, 1817) & Sardinha-bandeira & - & - & $18(3,4)$ & $100-81$ \\
\hline Biomassa total (número de exemplares) & & \multicolumn{2}{|c|}{$1598 \mathrm{~g} \mathrm{(264)}$} & \multicolumn{2}{|c|}{$2853 \mathrm{~g}(526)$} \\
\hline
\end{tabular}

fície d'água. Neste momento, se algum outro morcego cruzava sua área, era imediatamente perseguido até que se afastasse da área invadida, demonstrando assim, um comportamento territorialista. Quando a maré encontrava-se em seu nível mais baixo, muitos morcegos procuravam capturar insetos em vôo ou aqueles que caíam junto à superfície d'água. Estes insetos, geralmente mariposas (Lepidoptera) da Família Saturniidae foram capturados na maioria das vezes junto à superfície, sendo que em poucas ocasiões foram avistados morcegos capturando estes insetos em vôo. Durante a captura de peixes, foi possível observar que, durante vôos rasantes, os morcegos capturavam os peixes com os membros posteriores junto à superfície da água e em seguida, conduziam a presa para a boca e iniciavam o processo de mastigação. Durante as observações, N. leporinus mostrou uma taxa de sucesso de captura (número acertos/número tentativas) que variou de zero a $27 \%$ em suas investidas sobre os cardumes de peixes. Nas seções de observação sobre o comportamento de captura $(n=30)$, o número de tentativas sobre a presa e o sucesso na sua captura mostrou uma correlação negativa $(\mathrm{r}=-0,4682 ; \mathrm{p}<0,01)$.

\section{Variáveis abióticas e comportamento}

A temperatura do ar na Baía de Guaratuba variou ao longo do período de estudo de 4 a $28^{\circ} \mathrm{C}$. Não houve nenhuma correlação entre o número de morcegos em atividade e a temperatura ambiente, entretanto, a amplitude térmica ocupada pelos morcegos observados em atividade, variou de 12 a $28^{\circ} \mathrm{C}$.

Em relação à velocidade do vento, foi possível verificar que a atividade de vôo de $N$. leporinus na área de estudo, dimi- 
nuía quando o vento estava muito forte. Em um total de 20 seções de observação, foi registrada uma correlação negativa entre o número de animais em atividade de vôo e a velocidade do vento $(r=-0,8455 ; p<0,01)$. Ventos com velocidades variando de zero a $20 \mathrm{~km} / \mathrm{h}$, registraram as maiores médias de morcegos em atividade. A maior média de morcegos em vôo foi de 5,3 morcegos/h, em uma velocidade de vento de $20 \mathrm{~km} /$ h. A menor média foi de 0,16 morcegos/h para uma velocidade do vento de $80 \mathrm{~km} / \mathrm{h}$.

\section{DISCUSSÃO}

\section{Padrão de atividade}

Apesar de no presente estudo ter-se obtido os dados de atividade por meio de observação direta, o padrão de atividade noturna bimodal aqui encontrado para N. leporinus foi similar ao obtido por outros autores através de capturas com redesneblina, seja para N. leporinus (Almansa \& Martinez 1982), N. albiventris Desmarest, 1818 (FENTON et al. 1993), a qual apresentou basicamente dois picos noturnos.

Mesmo apresentando picos de atividade que variaram entre as estações do ano, no presente estudo N. leporinus utilizou basicamente todo o período noturno na sua atividade de forrageio, como observado também para outras espécies de morcegos com dieta insetívora (KUNz 1973) ou frugívora (MARINHO-Filho \& SAZIMA 1989). Este fato mostrou-se similar aos obtidos por BRown (1968) no Mar do Caribe, segundo o qual esta espécie utiliza forma mais ou menos uniforme todas as horas da noite. Por outro lado, a atividade contínua de N. leporinus diferiu dos resultados obtidos por Almansa \& Martinez (1982) na Venezuela, os quais verificaram em seu estudo que o morcego-pescador permanece cerca de cinco horas sem atividade durante a noite. Esta diferença de dados pode ser explicada pelos métodos de amostragem, pois aqueles autores utilizaram dados de captura em redes-neblina, o que poderia ocasionar erros de amostragem, caso os animais utilizassem mais de um local de forrageio noturno, podendo assim ocasionar uma falsa interpretação do seu comportamento.

De acordo com Fenton \& Kunz (1977), o ritmo de atividade das diferentes espécies de morcegos pode variar conforme a proximidade dos locais de refúgio noturno. Apesar de não ter sido localizado nenhum abrigo próximo ao local de observação da atividade dos morcegos, pode ser que este fator tenha sido uma variável importante, porém não avaliada nos resultados obtidos aqui para N. leporinus. Durante todo o estudo, não foi percebido qualquer influência no grau de luminosidade lunar sobre a atividade ou comportamento de N. leporinus, fato também verificado para outras espécies, como por exemplo, em Phyllostomidae (GAnNon \& Willig 1997).

Como o início do período noturno está condicionado à variação no horário do pôr-do-sol nas diferentes estações do ano, foi possível notar que nas estações de outono e inverno (de abril a setembro), o primeiro pico de atividade iniciava-se mais cedo e o segundo pico mais tarde do que nas estações de primavera e verão (de outubro a março), quando o período luminoso é maior e o noturno é menor. A maior amplitude no período de atividade de $N$. leporinus observada nos meses de inverno (julho a setembro) em relação às demais estações do ano, pode estar relacionada à maior dificuldade em encontrar alimento, a fim de suprir a necessidade de obter energia para a manutenção do calor corporal.

\section{Variação da maré e atividade de forrageamento}

O ritmo de atividade e comportamento de forrageamento em morcegos também pode estar relacionado muitas vezes à atividade de suas presas; sejam elas insetos (Kunz 1973) ou peixes (Romero 1985). A influência da maré sobre os cardumes de peixes mostrou ser uma condicionante do comportamento deste morcego no local de estudo. A influência exercida pela variação do nível da maré sobre o a atividade e comportamento de pesca de $N$. leporinus é também comentada por SCHNitzler et al. (1994), entretanto, ainda não havia sido relatada na literatura de forma mais detalhada.

Assim, apesar de não existirem estudos que expliquem o verdadeiro papel da variação da maré sobre a atividade de $N$. leporinus, de acordo com os dados obtidos na amostragem de biomassa de peixes na área de estudo, a disponibilidade de presas em um determinado local parece ser o fator condicionante do comportamento de pesca destes morcegos na Baía de Guaratuba.

\section{Variação da maré e disponibilidade de peixes}

Durante a maré baixa, a biomassa de presas disponível junto à margem foi cerca de 56\% menor do que na maré alta. As espécies de peixes comumente predadas por N. leporinus (conforme BORDIGNON \& FRANÇA 2002), também estiveram presentes em menor número, junto à margem, durante a maré baixa, indicando que a disponibilidade de presas neste período é menor do que na maré alta. Espécies da família Atherinidae, Engraulidae e Clupeidae, as quais foram mais capturadas na amostragem da maré alta junto à margem, são também as presas-alvo de $N$. leporinus, pois costumam deslocar-se junto à superfície d'água e em cardumes numerosos. Durante a maré bai$\mathrm{xa}$, os cardumes destes pequenos peixes possivelmente deslocam-se para águas mais profundas, para obterem uma área de fuga maior diante de outros peixes predadores, como por exemplo, o robalo (Centropomus parallelus Poey, 1860), obrigando os morcegos a deslocarem-se para águas mais profundas - e distantes da margem - para buscar alimento.

Na maré alta, quando a água inunda a margem formando uma lâmina d'água de pequena profundidade e com grande quantidade de matéria em suspensão, os cardumes de pequenos peixes migram junto com a maré à procura de alimento. Entretanto, os peixes de maior tamanho (predadores) não têm uma coluna d'água alta o suficiente para se deslocarem em busca de suas presas, desta forma, não podem predar os cardumes de pequenos peixes, os quais eventualmente são predados pelos morcegos.

Em peixes pequenos, o comportamento de procurar águas rasas foi observado também por Uieda et al. (1989) em cardu- 
mes de Tilapia rendalli (Boulenger, 1898) em um reservatório de água doce, onde os indivíduos de menor tamanho ocupavam sempre águas com até $50 \mathrm{~cm}$ de profundidade. Segundo os autores, este comportamento é justificado pela necessidade de buscar abrigo contra predadores, o que só é obtido, em águas mais rasas e junto à vegetação aquática.

Os dados obtidos no presente estudo reforçam a hipótese de que o deslocamento dos cardumes de pequenos peixes, ocasionado pela variação da maré, influencia o comportamento de pesca de N. leporinus na Baía de Guaratuba.

\section{Comportamento de captura de presas}

Como já registrada por Romero (1985), a atividade de pesca de $N$. leporinus em um determinado local está relacionada à disponibilidade de presas. Segundo SCHNitzler et al. (1994), o sucesso de captura de $N$. leporinus pode variar com a densidade dos cardumes no local de forrageio, possuindo geralmente uma taxa de sucesso de captura em torno de 0,5 a $4 \%$ e resultando em um tempo que varia de 8 a 60 minutos para a captura de um peixe. Mesmo não tendo sido possível estimar a densidade dos cardumes durante a atividade de pesca de N. leporinus, é provável que o sucesso de captura esteja mesmo relacionado à densidade de sua presa, pois a baixa taxa de sucesso encontrada aqui - cerca de 2,7 peixes a cada 10 tentativas - foi similar à encontrada por outros autores (Bloedel 1955, SCHNitzler et al. 1994), os quais puderam estimar a densidade de presas disponíveis nos locais de estudo.

\section{Variáveis abióticas e comportamento}

Apesar da temperatura ambiente influenciar a atividade metabólica dos morcegos através da modificação da temperatura corporal, como observado por Roverud \& CHAPPELL (1991) para outras espécies de morcegos, no presente estudo a atividade noturna de $N$. leporinus não mostrou nenhuma correlação com a temperatura ambiente. Por outro lado, a velocidade do vento influenciou a atividade dos morcegos na Baía de Guaratuba, pois o número de indivíduos observados foi inversamente proporcional à velocidade do vento. Os grupos de N. leporinus observados mostraram ter preferência a uma velocidade do vento variando de zero a $20 \mathrm{~km} / \mathrm{h}$. Isto parece lógico, pois ventos com mais de 20 ou $30 \mathrm{~km} / \mathrm{h}$ provocavam ondulações na superfície da água e isto certamente deve diminuir a eficiência na localização dos cardumes, pois segundo Schnitzler et al. (1994), este morcego utiliza o sistema de ecolocalização para detectar as ondulações na superfície d'água ocasionadas pelos cardumes de peixes. Além disso, ventos muito fortes atrapalham as manobras de vôo, dificultando a atividade de pesca e deslocamento.

Os dados obtidos no presente estudo mostraram que $N$. leporinus procura adaptar-se às variações ambientais e ao comportamento dos peixes, onde o deslocamento dos cardumes é influenciado pela variação no nível da maré, fazendo com que os grupos de morcegos-pescadores mudem seus locais de forrageamento ao longo de seu período de atividade.

Da mesma forma, o estudo da atividade noturna através de observações diretas e contínuas ao longo de todo o período noturno, mostrou que, dados sobre a atividade desta espécie de morcego e certamente de outras ainda não estudadas, obtidos somente através de capturas com redes, podem vir a mostrar uma visão pouco realista do período de atividade destes animais.

\section{AGRADECIMENTOS}

Ao CNPq e CAPES pelo financiamento deste estudo. Ao Curso de Pós Graduação em Zoologia da UFPR pelo incentivo. Aos revisores anônimos pelas sugestões à versão original. À Adriana de Oliveira França pelo apoio nas capturas e trabalho em laboratório e à Diretoria do Iate Clube de Caiobá pelo apoio logístico durante o trabalho de campo.

\section{REFERÊNCIAS BIBLIOGRÁFICAS}

Almansa, J.C. \& L.A. Martinez. 1982. Ritmo de actividad de cuatro especies de murcielagos neotropicales. História Natural, Corrientes, 2 (24): 213-220.

Altenbach, J.S. 1989. Prey capture by the fishing bats Noctilio leporinus and Myotis vivesi. Journal of Mammalogy, Lawrence, 70 (2): 421-424.

Altmann, J. 1974. Observational study of behavior: Sampling methods. Behaviour, Leiden, 49: 227-265.

Bloedel, P. 1955. Hunting methods of fishing-eating bats, particularly Noctilio leporinus. Journal of Mammalogy, Lawrence, 36: 390-399.

Blood, B. R. \& M.K. Clark. 1998. Myotis vivesi. Mammalian Species, Washington, 588: 1-5.

Bordignon, M.O. \& A.O. FrançA. 2002. Fish consumption by Noctilio leporinus (Linnaeus, 1758) in Guaratuba Bay, southern Brazil. Chiroptera Neotropical, Brasília, 8 (1-2): 148-150.

Brooke, A.P. 1994. Diet of the fishing bat, Noctilio leporinus (Chiroptera: Noctilionidae). Journal of Mammalogy, Lawrence, 75 (1): 212-218.

BRоOKE, A.P. 1997. Social organization and foraging behavior of the fishing bat, Noctilio leporinus (Chiroptera: Noctilionidae). Ethology, Berlin, 103: 421-436.

BRown, J.H. 1968. Activity patterns of some neotropical bats. Journal of Mammalogy, Lawrence, 49: 754-757.

Chaves, P.T.C. 1994. A incubação de ovos e larvas em Genidens genidens (Valenciennes) (Siluriformes, Ariidae) da Baía de Guaratuba, Paraná, Brasil. Revista Brasileira de Zoologia, Curitiba, 11 (4): 641-648.

Chaves, P.T.C. 1995. Atividade reprodutiva de Bairdiella ronchus (Cuvier) (Pisces, Sciaenidae) na Baía de Guaratuba, Paraná, Brasil. Revista Brasileira de Zoologia, Curitiba, 12 (4): 759766.

Chaves, P.T.C. \& A.L. Vendel. 1997. Reprodução de Stellifer rastrifer (Jordan) (Teleostei, Sciaenidae) na Baía de Guaratuba, Paraná, Brasil. Revista Brasileira de Zoologia, Curitiba, 14 (1): 8189. 
Cervantes, M.A. \& T.A. Solorzano. 1991. Notas sobre la dieta alimenticia del murcielago pescador Noctilio leporinus (Mammalia: Chiroptera). Anales de la Escuela Nacionale de Ciencias Biologicas del México, México, 35: 123-127.

EMMONS, L.H. \& F. FEER. 1990. Neotropical rain forest mammals: a field guide. Chicago, the University of Chicago Press, 290p.

Fenton, M.B. 1992. Bats. New York, Facts On File Incorporation, 207p.

Fenton, M.B.; D. Audet; D.C. Dunning; J. Long; C.B. Merriman; D. Pearl; D.M. Syme; B. Adkins; S. Pedersen \& T. Wohlgenant. 1993. Activity patterns and roost selection by Noctilio albiventris (Chiroptera: Noctilionidae) in Costa Rica. Journal of Mammalogy, Lawrence, 74 (3): 607-613.

Fenton, M.B. \& T.H. Kunz. 1977. Movements and Behavior. Special Publications of The Museum Texas Tech University, Lubbock, 13: 351-364.

Ferrarezzi, H. \& E.A. Gimenez. 1996. Systematic Patterns and the evolution of feeding habits in Chiroptera (Archonta: Mammalia). Journal of Comparated Biology, London, 1: 75-94.

Fish, F.E.; B.R. Blood. \& B.D. Clark. 1991. Hydrodynamics of the feet of fish-catching bats: influence of the water surface on drag and morphological design. Journal of Experimental Zoology, New Haven, 258: 164-173.

Gannon, M.R. \& M.R. Willig. 1997. The effect of lunar illumination on movement and activity of the red fig-eating bat (Stenoderma rufum). Biotropica, Lawrence, 29 (4): 525 529.

Handey Jr., C.O. 1976. Mammals of the Smithsonian Venezuelan Project. Brigham Young University Science Bulletin Biological Series, Provo, 20 (5): 1-89

Hood, C.S. \& J.K. Jones JR. 1984. Noctilio leporinus. Mammalian Species, Washington, 216: 1-7.

Jones Jr., J.K.; J.D. Smith \& H.H. Genoways. 1973. Annotated checklist of mammals of the Yucatan Peninsula, Mexico. 1. Chiroptera. Occasional Papers of The Museum Texas Tech University, Lubbock, 13: 1-31.

Koopman, K.F. 1982. Biogeography of the bats of South America. Pymatuning Laboratory of Ecology Especial Publication, Linesville, 6: 273-302.

KunZ, T.H. 1973. Resource utilization: temporal and spatial components of bat activity in Central Iowa. Journal of Mammalogy, Lawrence, 54 (1): 15-32.
KunZ, T.H. 1988. Ecological and Behavioral Methods for the Study of Bats. Washington, Smithsonian Institution Press, 533p.

LA VAL, R.K. \& H.S. Fitch. 1977. Structure, movements and reproduction in three Costa Rican bat communities. Occasional Papers of the Natural History Museum University of Kansas, Lawrence, 69: 1-28.

Ma, J.; G. Jones; S. Zhang; J. Shen; W. Metzner; L. Zhang \& B. LIANG. 2003. Dietary analysis confirms that Rickett's bigfooted bat (Myotis ricketti) is a piscivore. Journal of Zoology, London, 261: 245-248.

Marinho-Filho, J.S. \& I. Sazima. 1989. Activity patterns of six phyllostomid bat species in southeastern Brazil. Revista Brasileira de Biologia, Rio de Janeiro, 49 (3): 777-782.

NoWAK, R.M. 1994. Walker's Bats of the World. London, The Johns Hopkins University Press, 654p.

Novick, A. \& B.A. Dale. 1971. Foraging behavior in fishing bats and their insectivorous relatives. Journal of Mammalogy, Lawrence, 52: 817-818

Romero, A. 1985. Cave colonization by fish: role of bat predation. The American Midland Naturalist, Notre Dame, 113 (1): 7 12.

Roverud, R.C. \& M.A. Chappell. 1991. Energetic and thermoregulatory aspects of clustering behavior in the neotropical bat Noctilio albiventris. Physiological and Biochemical Zoology, Chicago, 64 (6): 1527-1541.

SchnitZler, H.U.; E.K.V. KalKo; I. Kaipf \& A.D. Grinnell. 1994. Fishing and echolocation behavior of the greater bulldog bat, Noctilio leporinus, in the field. Behavioral Ecology and Sociobiology, Berlin, 35 (5): 327-345.

Suthers, R.A. 1965. Acoustic orientation by fish-catching bats. Journal of Experimental Zoology, Hoboken, 158: 319-348.

Uieda, V.S.; W. Uieda; O. Froehlich \& M.E.C. Amaral. 1989. Organização de cardumes de Tilapia rendalli na Represa de Americana, São Paulo. Revista Brasileira de Biologia, Rio de Janeiro, 49 (3): 749-756.

Villa-Ramirez, B. 1966. Los murcielagos de Mexico. Mexico, Editorial Libros de México, 347p.

WILLIG, M.R. 1985. Reproductive patterns of bats from caatingas and cerrado biomes in northeast Brazil. Journal of Mammalogy, Lawrence, 66: 668-681.

Zórtea, M. \& L. Aguiar. 2001. Foraging behavior of the fishing bat Noctilio leporinus (Noctilionidae). Chiroptera Neotropical, Brasília, 7 (1-2): 140-142.

Recebido em 24.V.2005; aceito em 24.II.2006. 